\title{
Tempo de busca e de manuseio de larvas de Chrysoperla externa (Hagen, 1861) (Neuroptera, Chrysopidae) alimentadas com Uroleucon ambrosiae (Thomas, 1878) (Hemiptera, Aphididae)
}

\author{
Alexander M. Auad ${ }^{1}$ \\ Sérgio de Freitas ${ }^{1}$ \\ Leonardo R. Barbosa ${ }^{1}$
}

\begin{abstract}
Aвstract. Searching and handling time of Chrysoperla externa (Hagen, 1861) (Neuroptera, Chrysopidae) larvae fed on Uroleucon ambrosiae (Thomas, 1878) (Hemiptera, Aphididae). The objective of this research was to determine the searching and handling times of three larval instars of C. externa fed on U. ambrosiae at densities of 30, 40 and 50 per vial, with the feeding of the larvae at the preceding instars being U. ambrosiae nymphs or Sitotroga cerealella (Olivier, 1819) eggs. The larvae were maintained at $25 \pm 2{ }^{\circ} \mathrm{C}, 70 \pm 10 \% \mathrm{RH}$ and a 14-h photophase. A completely randomized design in a $6 \times 3$ factorial scheme with 12 replicates was adopted. The shortest searching time was found for the $2^{\text {nd }}$ and $3^{\text {rd }}$ instar larvae of C. externa, and this parameter was variable depending on the feeding given to the larvae previously. The handling time was similar for the $1^{\text {st }}, 2^{\text {nd }}$ and $3^{\text {rd }}$ instar larvae. The longest searching time was found at an aphid density of 30 , as compared to densities of 40 and 50 prey, with which there were no significant differences. Prey density did not have any influence on handling time.
\end{abstract}

KEYwORDs. Aphid; functional response; green lacewing.

\section{INTRODUÇÃO}

O pulgão Uroleucon ambrosiae (Thomas, 1878) é um inseto-praga em muitas plantas cultivadas e silvestres da família Compositae, algumas Gramineae e, entre as hortaliças, a alface é a principal hospedeira (PeÑa-MartineZ 1992).

O tempo de busca e de manuseio são componentes básicos e influenciam o modelo da resposta funcional (TOSTOWARKY 1972) que auxilia na determinação da eficiência do agente de controle biológico. $\mathrm{O}$ tempo gasto pelo predador para consumir o alimento requerido é um fator que interfere na sua eficiência e capacidade de busca (SundBy 1966).

Compreender as mudanças comportamentais e as interações do predador crisopídeo com um inseto-praga em função da densidade de presa, são atribuições da resposta funcional. Assim, pesquisas realizadas por ABLEs et al. (1978), SAMSON \& Blood (1980), Treacy et al. (1987), Stark \& Whttford (1987), Nordlund \& Morrison (1990), Y unsel \& Gocmen (1992), têm evidenciado diferentes tipos de respostas dos crisopídeos em função das espécies e quantidades de presas. Contudo, estudos desse predador com U. ambrosiae são inexistentes.

KABISSA et al. (1996) observaram uma resposta funcional do tipo II para os crisopídeos Mallada desjardinsi (Navás, 1911) e Chrysoperla congrua (Walker, 1853) alimentados com o afídeo Aphis gossypii Glover, 1877, mostrando também uma menor capacidade de busca e de manuseio da primeira espécie.

Com o afídeo Schizaphis graminum (Rondani, 1852), FonSECA et al. (2000) constataram maior consumo por larvas de Chrysoperla externa (Hagen, 1861) em função do aumento da densidade, assim como um menor tempo de busca para larvas de $2^{\circ}$ e $3^{\circ}$ ínstares e uma redução progressiva no tempo de manuseio de acordo com o desenvolvimento larval.

O objetivo do presente trabalho foi verificar o tempo de busca e de manuseio de larvas de C. externa nos três ínstares, alimentadas com U. ambrosiae, sendo a alimentação das larvas nos ínstares precedentes, ninfas desse afídeo ou ovos de 1. Departamento de Fitossanidade, Faculdade de Ciências Agrárias e Veterinárias, Universidade Estadual Paulista. Rodovia Paulo Donato Castelani,
$\mathrm{s} / \mathrm{n}^{\mathbf{o}}, 14870-000$ Jaboticabal-SP, Brasil. 
Sitotroga cerealella (Olivier, 1819) (Lepidoptera, Pyralidae).

\section{MATERIAL EMÉTODOS}

A criação do pulgão $U$. ambrosiae foi iniciada coletandose ninfas e adultos em plantas de alface cultivadas hidroponicamente no Colégio Técnico Agrícola da UNESP, Jaboticabal-SP, e transferidos para plantas de alface mantidas em casa de vegetação do Departamento de Fitossanidade.

Com relação a C. externa, coletaram-se adultos no Campus da UNESP-Jaboticabal, os quais foram mantidos em gaiola de PVC, com $23 \mathrm{~cm}$ de altura e $10 \mathrm{~cm}$ de diâmetro, vedadas na parte inferior e superior com tecido de "nylon". Internamente, foram revestidas com papel sulfite branco servindo como substrato de oviposição, e os adultos alimentados com levedo de cerveja e mel (1:1). Os ovos foram transferidos para recipientes plásticos de 5,5 $\mathrm{cm}$ de altura e $8 \mathrm{~cm}$ de diâmetro e as larvas alimentadas com ovos de $S$. cerealella. Os experimentos foram realizados utilizando-se larvas da geração F2.

Para determinação do tempo de busca e manuseio em cada ínstar de C. externa utilizaram-se ninfas de terceiro e quarto instares de $U$. ambrosiae confinadas em recipientes plásticos de 5,5 $\mathrm{cm}$ de altura $8 \mathrm{~cm}$ de diâmetro nas densidades de 30,40 e 50 presas. Os tratamentos e a alimentação (dieta) das larvas nos ínstares precedentes à sua utilização nos ensaios foram:

Tratamento 1: larvas de primeiro ínstar. Tratamento 2: larvas de segundo ínstar, alimentadas no primeiro ínstar com ovos de S. cerealella. Tratamento 3: larvas de segundo ínstar, alimentadas no primeiro ínstar com ninfas de $U$. ambrosiae.
Tratamento 4: larvas de terceiro ínstar, alimentadas no primeiro e segundo ínstares com ovos de S. cerealella. Tratamento 5: larvas de terceiro ínstar, alimentadas no primeiro ínstar com ovos de $S$. cerealella e, no segundo ínstar, com ninfas de $U$. ambrosiae. Tratamento 6: larvas de terceiro ínstar, alimentadas no primeiro e segundo ínstares com ninfas de $U$. ambrosiae.

As larvas foram individualizadas e mantidas a $25+2^{\circ} \mathrm{C}$, UR $70+10 \%$ e fotofase de 14 horas. Quatro horas após a eclosão ou a ecdise das larvas de segundo e terceiro ínstares, foi retirado todo o alimento das unidades de criação, mantendo-se as larvas em jejum por uma hora. Posteriormente foi liberada, no centro de cada recipiente, uma larva de $C$. externa e, através de um cronômetro, determinou-se o tempo de busca e manuseio, os quais foram avaliados para cada ínstar do crisopídeo, em função da alimentação utilizada precedentemente em cada estádio.

O delineamento foi inteiramente casualizado, em esquema fatorial 6x3 com 12 repetições, sendo os dados transformados em $\log \mathrm{x}$. Posteriormente, foram submetidos à análise de variância $(\mathrm{P}<0,05)$, e as médias foram comparadas pelo teste de Tukey $(\mathrm{P}<0,05)$.

\section{RESULTADOS E DISCUSSÃO}

O tempo de busca de larvas de C. externa alimentadas com de ninfas de $U$. ambrosiae foi dependente do estádio do predador, da alimentação prévia das larvas e do número de afídeos disponível. Para larvas de primeiro ínstar, foi significativamente maior quando comparado aos dos demais (Tabela I). Isto ocorreu devido ao volume corporal da larva de

Tabela I. Tempo de busca e de manuseio de larvas de Chrysoperla externa nos três ínstares utilizando-se ninfas de terceiro e quarto ínstares de Uroleucon ambrosiae, em diferentes densidades; $25 \pm 2 \mathrm{oC}$, UR $70 \pm 10 \%$ e fotofase $14 \mathrm{~h}$; Jaboticabal, SP.

\begin{tabular}{|c|c|c|c|}
\hline Tratamentos & $\begin{array}{c}\text { Instar e } \\
\text { Alimento usado } \\
\text { precedentemente }\end{array}$ & $\begin{array}{l}\text { Tempo de busca } \\
\text { (h, min., seg.) }\end{array}$ & $\begin{array}{l}\text { Tempo de manuseio } \\
\text { (h, min., seg.) }\end{array}$ \\
\hline 1 & $1^{\circ}$ & 1:18'36' a & $0: 25^{\prime} 02^{\prime} \mathrm{ab}$ \\
\hline 2 & $2^{\circ} \mathrm{S}$ & $0: 40$ '29' b & $0: 28^{\prime} 04^{\prime \prime}$ a \\
\hline 3 & $2^{\circ} \mathrm{U}$ & $0: 25^{\prime} 19^{\prime \prime} \mathrm{b}$ & $0: 19^{\prime} 32^{\prime \prime} \mathrm{ab}$ \\
\hline 4 & $3^{\circ} \mathrm{S}+\mathrm{S}$ & $0: 17 ’ 21^{\prime \prime}$ bc & $0: 12^{\prime} 31^{\prime \prime} \mathrm{ab}$ \\
\hline 5 & $3^{\circ} \mathrm{S}+\mathrm{U}$ & $0: 14$ '43' cd & $0: 15^{\prime} 35^{\prime \prime} \mathrm{ab}$ \\
\hline \multirow[t]{5}{*}{6} & $3^{\circ} \mathrm{U}+\mathrm{U}$ & $0: 06 ' 05^{\prime \prime} \mathrm{d}$ & $0: 08 ' 56$ ' b \\
\hline & Densidades de & & \\
\hline & 30 & $0: 43 ' 57^{\prime \prime}$ a & $0: 19^{\prime} 47^{\prime \prime} \quad$ a \\
\hline & 40 & $0: 24 ' 59^{\prime \prime} \mathrm{b}$ & $0: 18^{\prime} 02^{\prime \prime} \quad$ a \\
\hline & 50 & $0: 22^{\prime} 21^{\prime \prime} \mathrm{b}$ & $0: 17^{\prime} 02^{\prime \prime} \quad$ a \\
\hline
\end{tabular}

Médias seguidas por letras distintas, nas colunas, diferem entre si pelo teste de Tukey $(\mathrm{P} \leq 0,05) . \quad \mathrm{S}=$ S. cerealella; $\mathrm{U}=U$. ambrosiae. 
C. externa ser menor que o do afídeo.

No segundo ínstar, não houve variação no tempo de busca em função da alimentação no estádio inicial da larva, resultados que se aproximaram dos obtidos por NordLund \& MORRISON (1990), os quais demonstraram a não intensificação na busca de A. gossypii por larvas de Chrysoperla rufilabris (Burmeister, 1839), mesmo quando previamente alimentadas com a mesma presa. Nesse ínstar, as larvas apresentaram menor tempo de busca que no precedente, não diferindo daquelas de terceiro ínstar, que se alimentaram nos ínstares anteriores com ovos de $S$. cerealella (Tabela I). Esses resultados assemelharam-se àqueles obtidos por FonSECA et al. (2000), no estudo do tempo de busca de $S$. graminum por larvas de $C$. externa.

As larvas de terceiro ínstar, independentemente da alimentação empregada anteriormente, mostraram-se mais ágeis que aquelas dos demais estádios; exceto aquelas do tratamento 4, alimentadas nos ínstares anteriores com ovos de $S$. cereallella, cujo tempo de busca não diferiu significativamente do tempo apresentado pelas larvas de segundo ínstar. Para as larvas, nesse estádio de desenvolvimento, pode-se verificar que o tipo de alimento ingerido nos ínstares precedentes influenciou a sua capacidade de busca. Quando as larvas receberam $U$. ambrosiae nos dois primeiros ínstares, o tempo de busca foi significativamente menor quando comparado ao das larvas que receberam apenas ovos de $S$. cereallella, e não diferiram daquelas alimentadas com ovos do piralídeo durante o primeiro ínstar e com pulgões no segundo ínstar (Tabela I). O fato de as larvas alimentarem-se nos ínstares anteriores com pulgão facilitou e aumentou a capacidade de busca do predador, evidenciando um processo de aprendizagem.

Em relação ao tempo de busca das larvas de $C$. externa por ninfas de $U$. ambrosiae em função da densidade de presa utilizada, verificou-se que o tempo médio na densidade 30 foi maior que nas demais densidades. Com 40 e 50 presas, não foram constatadas diferenças, independentemente do ínstar, constatando-se que nessas densidades os encontros ao acaso são maiores, reduzindo o tempo de busca pelas larvas de $C$. externa.

O tempo de manuseio das ninfas de $U$. ambrosiae por larvas de C. externa, variou em função do estádio do predador; contudo, o mesmo não ocorreu quando as larvas foram oriundas de diferentes regimes alimentares (Tabela I), como constatado por NORDLUND \& MORRISON (1990), em que o tempo de manuseio de larvas de segundo e terceiro ínstares de $C$. rufilabris alimentadas com $A$. gossypii não foi influenciado pela dieta anterior dada a esse predador.

Foi constatada uma tendência para um prolongamento do tempo de manuseio por larvas de primeiro e segundo ínstares. Porém, os resultados não foram significativamente diferentes daqueles constatados para larvas de terceiro ínstar. Para aquelas de segundo ínstar e preliminarmente alimentadas com ovos de S. cerealella, esse parâmetro foi maior (Tabela I). Esses resultados foram discrepantes dos encontrados por FonsECA et al. (2000), em que o tempo de manuseio de larvas de $C$. externa, alimentadas com $S$. graminum, teve uma menor duração para larvas de terceiro ínstar. Isso possivelmente se deve ao fato das larvas nesse estádio apresentarem maior volume corporal em relação ao volume da presa.

A proximidade entre as médias obtidas para o tempo de manuseio de larvas de primeiro, segundo e terceiro ínstares de C. externa alimentadas com ninfas de $U$. ambrosiae (Tabela I), pode ser explicada pelo comportamento daquelas de primeiro ínstar ao se alimentarem desse afídeo. Por serem menores que a presa, logo ficavam saciadas, deixando o pulgão morto, porém ainda com hemolinfa. Ao contrário dessas, as larvas de terceiro ínstar sugavam toda a hemolinfa deixando somente o exoesqueleto do pulgão. Dessa forma, a maior quantidade de alimento necessária para saciá-las e, conseqüentemente, o maior tempo de manuseio, contribuíram para a similaridade entre as médias obtidas para os três estádios.

O tempo de manuseio não foi influenciado pela densidade da presa, apesar de apresentar uma tendência de ser menor à medida que a densidade aumenta (Tabela I). Segundo IsENHOR \& YeRGAN (1981), a maior atividade das presas em altas densidades faz com que a presa, ao encostar no predador, interrompa a sua alimentação, sendo esse comportamento mais comum quando se encontram confinados, o que também poderá ocorrer em condições naturais, em função da agregação dos pulgões.

Agradecimentos. À Fundação de Amparo à Pesquisa do Estado de São Paulo, FAPESP, pelo auxílio financeiro para execução do trabalho.

\section{REFERÊNCIAS}

Ables, J.R.; S.L. Jones \& D.W. Mccommas JR. 1978. Response of selected predator species to different densities of Aphis gossypii and Heliothis virescens eggs. Environmental Entomology 7(3):402-404.

Fonseca, A.F.; C.F. Carvalho \& B. Souza. 2000. Resposta funcional de Chrysoperla externa (Hagen, 1861) (Neuroptera: Chrysopidae) alimentada com Schizaphis graminum (Rondani, 1852) (Hemiptera: Aphididae). Anais da Sociedade Entomológica do Brasil 29(2): 309-317.

Isenhor, D.J. \& D.J. Yergan. 1981. Predation by Orius insidiosus (Say) on the soybean thrips, Sericothrips variabilis: effect of prey stage and density. Environmental Entomology 10(4):496-500.

Kabissa, J. C. B.; J. G. Yarro; H. Y. Kayumbo \& S. A. Juliano. 1996. Functional response of two chrysopid predators feeding on Helicoverpa armigera (Lep.: Noctuidae) and Aphis gossypii (Hom.: Aphididae). Entomophaga 41(2):141-151.

Nordlund, D.A. \& R.K. Morrison. 1990. Handling time, prey preference and functional response for Chrysoperla rufilabris in the laboratory. Entomologia Experimentalis et Applicata 57: 237-242.

Peña-Martinez, R. 1992. Diagnosis de las especies, p.21-86. In: C.M. Urias; M.R. Rodriguez \& A.T. Alejandre (eds). Afidos como vetores de vírus en México. México, Centro de Fitopatologia, vol. 2, $135 \mathrm{p}$.

Samson, P.R. \& P.R.B. Blood. 1980. Voracity and searching ability of Chrysopa signata (Neuroptera: Chrysopidae), Micromus tasmaniae (Neuroptera: Hemerobiidae) and Tropiconabis capsiformis (Hemiptera: Nabidae). Australian Journal of Zoology 28:575-580.

StARK, S.B. \& F. WhTtFord. 1987. Functional response of Chrysopa carnea (Neur.: Chrysopidae) larvae feeding on Heliothis virescens (Lep.:Noctuidae) eggs on cotton in field cages. Entomophaga 32(5):521-527.

SunDBY, R.A. 1966. A comparative study of the efficiency of three preda- 
tory insects Coccinella septempuctata L. (Coleoptera, Coccinellidae), Chrysopa carnea St. (Neuroptera, Chrysopidae) and Syrphus ribesii L. (Diptera, Syrphidae) at two different temperatures. Entomophaga 11(4):395-405.

Tostowaryk, W. 1972. The effect of prey defense on the functional response of Podisus modestus (Hemiptera: Pentatomidae) to densities of the sawflies Neodiprion swainei and N. Pratti banksianae (Hymenoptera: Neodiprionidae). Canadian Entomology 104:61-69.
Treacy, M.F.; J.H. Benedict; J.D. Lopez \& R.K. Morrison. 1987. Functional response of a predator (Neuroptera: Chrysopidae) to bollworm (Lepidoptera: Noctuidae) eggs on smoothleaf, hirsute, and pilose cottons. Journal of Economic Entomolology 80(2):376379.

Yuksel, S. \& H. Gocmen. 1992. The effectiveness of Chrysoperla carnea (Stephens) (Neuroptera, Chrysopidae) as a predator on cotton aphid Aphis gossypii Glov. (Homoptera, Aphididae). Proceedings of the Turkish National Congress of Entomology 2:209-216. 